\title{
Study on the Causes and Countermeasures of the Lexical Collocation Mistakes in College English
}

\author{
Hansheng Yan \\ School of Foreign Languages, Qingdao University of Science and Technology, Qingdao 266061, China \\ E-mail: hanshengyan2006@yahoo.com.cn
}

\begin{abstract}
The lexical collocation in English is an important content in the linguistics theory, and also a research topic which is more and more emphasized in English teaching practice of China. The collocation ability of English decides whether learners could masterly use real English in effective communication. In many years' English teaching practice, the author found that many college students often ignored the learning and study of the target language collocation, so they would make many collocation mistakes in English writing, dialog, and exams. The main representations and causes of these mistakes are analyzed in this article, and the main countermeasures of these mistakes would be proposed for teachers' teaching and students' learning.
\end{abstract}

Keywords: Lexical collocation, Language situation, Collocation mistakes, Countermeasures

\section{Important meanings of the correct English lexical collocation}

English linguist Wilkins said that "if there is no grammar, there are not many expressed things, and if there is no glossary, no things can be expressed". To learn and grasp certain quantity glossaries can learn the grammar well, or else, the grammar will be a bare outline, but glossaries are not isolated, there are different rules of composition and application situation among glossaries, which needs learners to grasp different meanings of the glossaries, the tiny difference with the thesaurus, the special language situation and relative syntactic function with other glossary combinations. It is more important to choose proper lexical collocation aiming at different language situations than the grammar structure.

In English learning, many students take the amount of English word as the main standard to measure the ability of English learning, and it seems that memorizing many words could freely use this language, but in fact, the more important is to know the relation among words, properly combine words, phrase, sentences, and lexical chunks. Some linguists said that it was more important to know the fellowship of one word.

\section{Main types of lexical collocation and main representations of the lexical collocation mistakes}

(1) The type of "verb + noun", such as "pay off one's debts", "draw a conclusion", "get into an argument", and "take a break".

(2) The type of "noun + noun", such as "newspaper kiosk", "traffic accident", and "protest rally".

(3) The type of "preposition + noun", such as "in agony", "at speed", "in writing", and "at Christmas".

(4) The type of "adjective + noun", such as "strong wind", "heavy rain", "a crushing defeat", and "a convincing win".

(5) The type of "phrasal verbs collocation", such as "rely on", "dry up", "hang on to", and "look after".

(6) The type of "verb + preposition + noun", such as "speak in English", and "go on a bus".

(7) The type of "measure word + preposition + noun", such as "a drop of water", "a piece of jewellery" and "a snatch of conversation".

According to the characteristics of lexical collocation, linguist Lewis classified the lexical collocation into the tight type, the loose type such as "carry out a study" and "hold a meeting", the central type, and the tight type with strict combination such as "rancid butter".

In about 300 non-English specialty students' English writing of Qingdao University of Science and Technology, two kinds of lexical collocation mistake occurred in most frequency, and the first one is the collocation of "verb + noun" which occupies about $50 \%$ of all lexical collocation mistakes, for example, taking "answer the telephone" as "receive the telephone" and taking "take advantage of" as "make advantage of", especially, and several verbs such as "make, do, take and have" with strong collocation capacity would be often misused with the object.

The second one is the structured mistake of "adjective + noun", which occupies about $25 \%$ of all lexical collocation mistakes. For example, the "busy traffic" or "heavy traffic" would often be translated as "crowded traffic". The mistake of "noun + noun" collocation was less, because the use of this collocation was also less. 
The another cause of frequent lexical collocation mistake is the wrong instructions in some domestic teaching materials and some English teachers, because these lexical collocations are right and occur in teaching materials, but they are not accepted or used in actual life of the countries which take English as the mother language. For example, for the type of "adverb + adjective", some students would say that "She is very crazy/ very mad" when they wanted to describe someone was angry, and though the grammar was right, but people in English countries would not say that, and they would say, "She is absolutely crazy/ absolutely mad", and they would not say, "She become crazy/ became mad", but "She went crazy/ went mad". After many years' English learning, college students could express basic life topics in English, but it is very difficult to talk and write by real English, and few of them could achieve this level, and it needs a firm foundation of English language. For people in English countries, the lexical collocations could be predictable, the collocated words would automatically occur when main word appears, but for language learners, it is unpredictable.

\section{Main causes of lexical collocation mistakes}

\subsection{Partial understanding or misunderstanding for lexical meanings}

With the further study of English, the complexity and ambiguity of the glossaries will often make learners feel confused, and many collocation mistakes would occur in concrete using. For example, if students don't know the word of "flood" has the meaning of "disaster", they will often use the fault collocation such as "flood disaster". It is also wrong to use the "productivity force" to denote the meaning of "productivity".

\subsection{Synonyms copying and thesaurus mischoosing}

College students would often use the lexical collocation which only accords with the former language situation in new language situation. And they would often extend and use some lexical collocation rules without considering the exception and limitation of the special language situation, for example, they would write "do good to or do bad to" according to "do harm to", and write "gain harvest" according to the meaning of "obtain" of "gain" in "gain recognition or gain experience", but the right collocation should be "reap harvest". Though "drive a car" is right, but it is wrong to say, "Drive a bike", and the right collocation should be "Ride a bike". Students would often put off the objects of many words such as "make, do, get, have", for example, they would often write "make a gesture" as "do a gesture", and write "take a photo" as "make a photo". It was often ignored to choose different lexical collocations according to the language situation in the context, for example, students would often use the word of "hide" to denote the meaning of "conceal", such as "Several pistols were hidden in the back of the car".

The collocation rules are decided by the present language situation, not in any occasion. For example, when the word of "grasp" is to denote the meaning of "tackle or seize", it can be decorated by the adverb of "tightly", for example, "The little girl grasped her mother tightly by the wrist while crossing the street", but when it is used to denote the meaning of "understand or known", it could not be decorated by the adverb of "tightly".

Students often would not know how to properly use the word to express right meaning in formal or informal occasions, for example, "return" is more formal than "bring back or take back", and "tough" is more general and relaxed than "strict or harsh", and "superior" is more formal than "better".

\subsection{Influences of native language}

Most lexical collocation mistakes are related with the native language. Foreign language learners would intentionally or unintentionally associate or compare the foreign language with their native language, which would induce unequal associations or collocation mistakes because of the thinking mode of native language. For example, students would often replace "take medicine" by "eat medicine", and replace "read a novel" by "look a novel". "The food wasn't enough" is the expression of "Chinese English", and the right expression should be "There wasn't enough food", and "enough" should be put before the retouched noun, but when it decorates a adjective, it should be put behind the adjective, for example, "He is not old enough to drive a car".

\section{Countermeasures of lexical collocation mistakes}

First, learners should realize the importance of lexical collocation, and teachers should also put it on the important state in the teaching outline of English. In recent years, the selected teaching materials in colleges all arrange the exercises of lexical collocation, and offer some practical collocation exercises, but there is still largely improved space. For example, the glossaries involved in these exercises are less, and the exercise form is single, and theoretical explanation is shallow, which can not effectively enhance students' ability in lexical collocation. Aiming at learning on different levels, teachers could design various lexical collocation exercises. For example, to train the collocation structure of "+ noun", teachers could use the collocation of "predicate verb + noun" to train students' ability of lexical collocation.

a. We have to take part-time jobs to clear/pay off/pay up his debts.

b. We did/took/went on a trip to a nearby village by bus.

c. I put up my hand to shade/shelter/shield my eyes from the sun. 
d. Mr. Li came up with/presented/put forward the suggestion that I should take a job to support my family.

e. The supervisor refused to accept/receive/shoulder the blame for the accident.

\section{f. A meeting had been arranged/scheduled/programmed for next week}

g. The scientists failed to arrive at /decide/draw any conclusions from the study.

The exercise of error correction for the lexical collocation could be designed, for example, requiring students to replace the wrong adverbs in the sentence by correct adverbs (correct answer is in the brackets).

a. He argued hotly about he right to ask for leave. (fiercely/heatedly)

b. He grinned owlishly at her. (sheepishly/wolfishly)

c. The tragic story markedly illustrates how vulnerable children can be. (brutally)

d. I woefully confessed to having forgotten the key. (ruefully)

Teachers also can require students to correct the mistakes in one article or one sentence by the dictionary. For example, "While I am away, could you please have (keep) an eye on my suitcase?"

They can design the exercise of identification. They list some nouns, and some of them could be collocated with certain verb, but some of them could not. Teachers can require students to find out the nouns which could be collocated with the verb, for example, students are required to find out the words which can be used with "make" in following words, "1. an impression, 2. noise, 3. a nap, 4. a fuss, 5. an idea, 6. a party, 7. an effort, 8. a cake, 9. a cold, 10 .a decision", where the words of "1.2.4.7.8.10" can be collocated with "make".

Teachers could select one section of the article, and empty the glossaries in lexical collocation, and require students to fill the blanks and rehearse this article, which can strengthen students' memories for the lexical collocation.

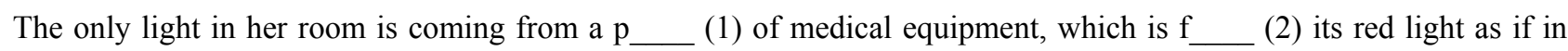
warning. As I stand there, the smell hits my nose, and I close my eyes as I remember the smell of decay from $p$
experience, in my mouth I have a s
(4) taste coming from the $p$
(5) of my stomach. I r
(6) for the light

switch, and as it silently lights the scene, I r

(7) to the bed to observe the patient with an unemotional, medical eye.

Answers: (1) piece (2) flashing (3) past (4) sour (5) pit (6) reach (7) return.

A good lexical collocation dictionary is necessary for learners who want to further enhance their English level. The "Oxford Collocations" published by the Oxford University Press in 2006 has about ten thousands words including nouns, verbs and adjectives, and it contains the language situation and collocations of most words for middle and high level learners, and includes 50000 example sentences which could exactly and vividly reflect the application of lexical collocation in practical life.

The "Longman Essential Activator" chiefly compiled by Rundell M could also definitely instruct the lexical collocation, and all examples in this book were selected in the linguist database of English countries, and the language was natural and real, which could help learners to grasp the correct collocation of the glossaries.

Each English learner will unconsciously establish a mental glossary or lexical collocation glossary in the learning process, for example, for the word of "familiar", you will associate it with "be familiar to or be familiar with", and once you see "dog", you will think of "bark", and when you see "cat", you will think of "meow". These accumulated mental glossaries depend on large numerous reading to fulfill and extend, and with large stocks, you can have English words at hand when you write or speak, and your English will be more accurate, abundant or real.

The establishment and continual perfection of various linguist databases will make the teaching and learning of lexical collocation more matured and standard. By the linguist databases established by the people in English countries, such as the Brown database, BNC and Lob database, learners could acquire real lexical collocation and examples. In the teaching of English and lexical collocation, the language database is the most convenient and useful assistant teaching tool for teachers.

The learning and grasping of lexical collocation are a long-term process, and foreign language learners will inevitably make mistakes in the lexical collocation, but the more important is to analyze the summarize the cause, characteristic and type of these mistakes, and find out the rule of these lexical collocation mistakes in Chinese English learners, and continually check, perfect and exercise these mistakes. Only in this way, the English learning of Chinese learners will be really enhanced.

\section{References}

Klauser. (2006). Dictionary of Oxford Collocations. Shanghai: Shanghai Foreign Language Education Press.

Leech, G. N. (1994). Semantics: The Study of Meaning. Edinburgh University Press.

Luo, Jiansheng. (2004). Function of Collocation in the Form and Communication of Discourse. Journal of 
South-central University for Nationalities. No.20(2). P.111-114.

Sun, Lan. (2006). On Mental Lexicon from the Perspective of Cognitive Constraints. Foreign Language Education. No. 4.

Wei, Naixing. (2002). Corpus-driven Approaches to the Study of Collocation. Contemporary Linguistics. No.4(2). P.101-104.

Xu, Lixin. (2001). Lexical Collocation in Discourse. Foreign Languages and Their Teaching. No.2. P.29-32. 